\title{
Presence of the European polecat, Mustela putorius Linnaeus, 1758 (Mammalia Mustelidae), in Aspromonte National Park, Italy
}

\author{
Giacomo Gervasio ${ }^{*}$,Antonino Siclari², Sergio Tralongo², Salvatore Urso' \& Francesca Crispino' \\ ${ }^{1}$ Società Greenwood, via Pozzillo 21, 87045 Dipignano, Cosenza, Italy \\ ${ }^{2}$ Ente Parco Nazionale dell'Aspromonte, Via Aurora, 89057 Santo Stefano in Aspromonte, Reggio Calabria, Italy \\ *Corresponding author, email: giacomogervasio@greenwoodstudiecologici.it
}

\begin{abstract}
In the recent past, the presence of the European polecat, Mustela putorius Linnaeus, 1758 (Mammalia Mustelidae), in the Aspromonte National Park (Italy) appears to be uncertain due to the lack of objective data and specific studies. In 2017-2018, the Park Authority carried out a project to monitor seven species of mesocarnivores whose status is poorly known even at the local level. Monitoring was performed by means of camera trapping, a technique particularly suitable for the detection of very elusive species. During the second year of activity, the presence of the European polecat was recorded in two different areas of the north-eastern side of Aspromonte National Park, the southernmost part of its Italian distribution.
\end{abstract}

KEY WORDS Mustela putorius; presence; demography; mustelids; Aspromonte.

Received 28.02.2019; accepted 09.04.2019; published online 24.05.2019.

\section{INTRODUCTION}

The European polecat, Mustela putorius Linnaeus, 1758 , is a small carnivorous mammal of the family Mustelidae recognizable by its characteristic light facial mask. The species can live in very different habitats, generally below $1500 \mathrm{~m}$ a.s.l. It can be found in ruderal zones, in various forest formations, in landfills or in wet environments, which it prefers. However, it generally favours areas with little human presence. In Europe, the polecat is distributed from the Iberian Peninsula to the Urals, with its northern limit being Wales, Sweden and southern Finland. In Italy, it is present in most of the peninsula, probably in a discontinuous manner, but is lacking in Sardinia and Sicily. The species is considered to be declining throughout Europe, albeit locally stable (Weber, 1988; Lodé, 1988).
Historical information on the European polecat in Aspromonte National Park is not particularly precise, given the lack of reliable reference data. Moschella (1900) reported its presence in the province of Reggio Calabria. In the Park Plan (AA.VV., 2009), the species is indicated as only potentially present, even though there are many suitable environments within the Park. In 2017, the Park Authority carried out a project to monitor seven species of mesocarnivores by means of camera trapping: red fox Vulpes vulpes Linnaeus, 1758, European badger Meles meles (Linnaeus, 1758), pine marten Martes martes (Linnaeus, 1758), beech marten Martes foina (Erxleben, 1777), European polecat M. putorius, least weasel M. nivalis Linnaeus, 1766, and European wildcat Felis silvestris Schreber, 1777. Particular attention was given to the collection of data on the European polecat on account of the lack of knowledge about its status, even at the local level. 


\section{MATERIAL AND METHODS}

Monitoring was performed by means of camera trapping, a technique considered particularly suitable for the detection of very elusive species. The methodological approach was opportunistic, aimed at recording presence data in sample areas. The choice of trapping stations was based on studies of the ecological requirements of the various species and on a careful landscape analysis to identify the different environmental types representative of the study area. During the camera trap positioning, particular attention was given to the identification of runs, trails and ditches located near wet areas. For the surveys carried out in 2017, 15 stations were identified. In some of them considered particularly suitable, an additional camera trap was positioned to increase the capture possibilities. In total, 20 camera traps have been active for 4 weeks (from mid-February to mid-May) in different recording sessions. In 2018, the sampling strategy was revised to further maximize the possibility of positive results. Compared to the previous year, additional camera trapping sessions were performed on the north-eastern side of the Park and in other sample areas thought to be particularly favourable but not covered by the previous surveys. In this phase, 9 trapping stations were identified and 12 camera traps were set up, which remained active for a continuous session of 12 weeks (from mid-March to mid-June). In both years, the camera traps have been positioned at a height of $30-50 \mathrm{~cm}$ above ground near wildlife runs. Olfactory bait-attractants were used to attract the species to the camera trap.

\section{RESULTS AND CONCLUSIONS}

The monitoring activities carried out in 2017 2018 recorded 13 species of wildlife, including the certain presence of the European polecat in two different areas on the north-eastern side of Aspromonte National Park. In both cases, the trapping stations were chosen at the edges of watercourses with abundant cover of shrub and riparian vegetation, respectively at an altitude of $170 \mathrm{~m}$ a.s.l. and $575 \mathrm{~m}$ a.s.l. Table 1 summarizes the camera trapping data for the European polecat.

The European polecat was recorded only in the second year of activity and with a very small number

\begin{tabular}{|cccccc|}
\hline $\begin{array}{c}\text { Station } \\
\text { ID }\end{array}$ & Period & $\begin{array}{c}\text { Recording } \\
\text { time }(\mathrm{h})\end{array}$ & $\begin{array}{c}\text { No. } \\
\text { independent } \\
\text { contacts }\end{array}$ & $\begin{array}{c}\text { Time of } \\
\text { record }\end{array}$ & $\begin{array}{c}\text { Trap } \\
\text { rate }\end{array}$ \\
\hline 2 & $\begin{array}{r}15 / 03 / 2018 \\
17 / 06 / 2018\end{array}$ & 2224 & 1 & $03: 36$ & 0.04 \\
\hline 4 bis & $15 / 03 / 2018$ & 2230 & 1 & $20: 41$ & 0.04 \\
& $17 / 06 / 2018$ & & & & \\
\hline
\end{tabular}

Table 1. Recording time expressed in hours of operation; number of independent contacts (i.e. photos of individuals of the same species taken at least 1 hour apart or of morphologically distinguishable individuals); trap rate (number of independent contacts/monitoring hours *100).

of independent contacts. This demonstrates the difficulty of recording a species with particularly low densities and confirms the need to keep the photographic equipment in the field for sufficiently long times to detect the species' presence (Fusillo \& Marcelli, 2014). Prior to this study, knowledge of the presence of the European polecat in the Aspromonte area was based on bibliographical reports from the last century (Moschella, 1900) and on considerations of its potential presence with reference to the availability of suitable habitats (Park Plan). Therefore, our results should be considered the first certain record of the recent presence of the species in the southernmost part of its Italian distribution range.

\section{REFERENCES}

AA.VV., 2009. Piano del Parco Nazionale dell'Aspromonte (ultima revisione gennaio 2007, pubblicato su G.U n ${ }^{\circ} 15$ del 28 gennaio 2009).

Fusillo R. \& Marcelli M., 2014. Il gatto selvatico, la martora e altri mammiferi nel Parco nazionale del Cilento, Vallo di Diano e Alburni. Fototrappolaggio, distribuzione ed ecologia. Edito da Ente Parco Nazionale del Cilento, Vallo di Diano e Alburni. Quaderni della Biodiversità n. 1, 285 pp.

Lodé T., 1988. Note préliminaire sur la biologie du comportement du putois (Mustela putorius L. 1766) dans les bocages humides de l'Ouest de la France. Bulletin de la Société des Sciences Naturelles de l'Ouest de la France, N.S., 10: 58-67.

Moschella G. 1900. I Mammiferi di Reggio Calabria, ovvero sguardo sulla mammalofauna locale. Stabilimento Tipografia F. Morello, Reggio Calabria, 35 pp.

Weber D., 1988. Die aktuelle Verbreitung des Iltisses (Mustela putorius L.) in der Schweiz. Revue suisse de Zoologie, 95: 1041-1056. 